$$
\text { تأثير آب مغناطيسى بر برخى از يارامترهاى رشدى و بيوشيميايى در زياه كدو خورشتى سميت علف تريفلى تحلين }
$$

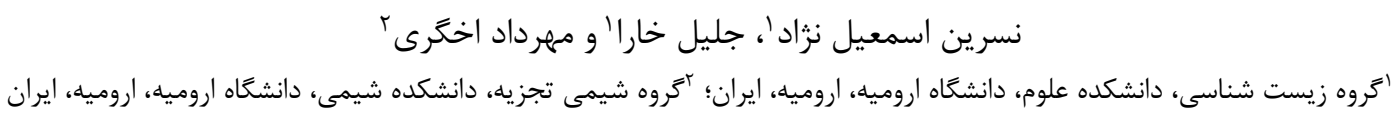

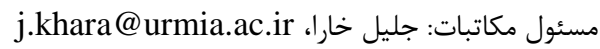

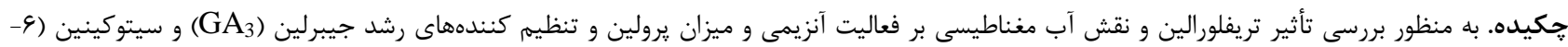

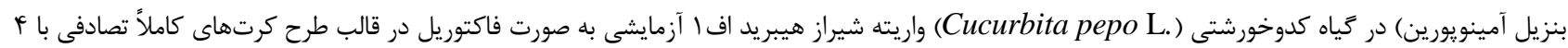

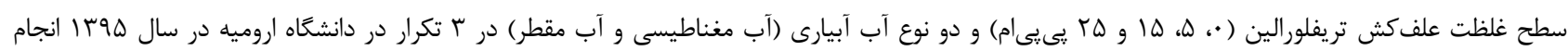

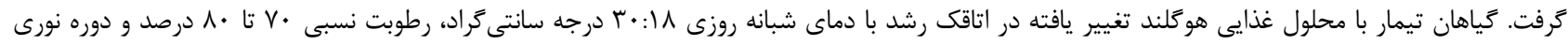

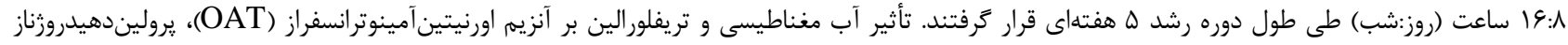

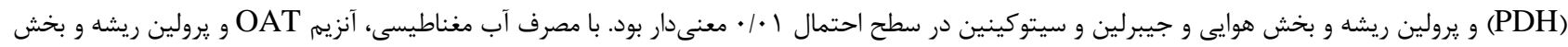

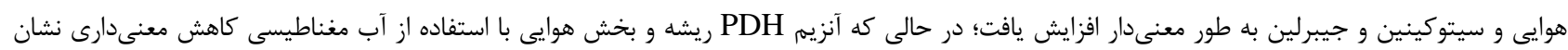

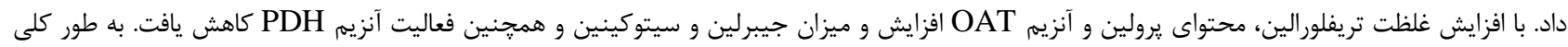

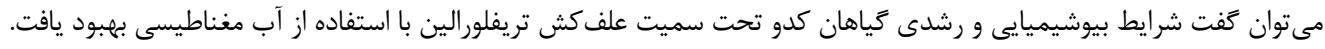

$$
\text { وازههاى كليدى. اورنيتين آمينوترانسفراز، يرولين، يرولين دهيدروزناز، جيبرلين، سيتوكينين }
$$

\title{
The effect of magnetized water on the growth and some biochemical parameters of squash (Cucurbita pepo) plants under toxicity of herbicide trifluralin
}

\author{
Nasrin Esmailnejad ${ }^{1}$, Jalil Khara ${ }^{1}$ \& Mehrdad Akhgari ${ }^{2}$ \\ ${ }^{1}$ Department of Biology, Faculty of Sciences, Urmia University, Urmia, Iran; ${ }^{2}$ Department of Analytical Chemistry, \\ Faculty of Chemistry, Urmia University, Urmia, Iran \\ Correspondent author: Jalil Khara, j.khara@urmia.ac.ir
}

\begin{abstract}
To investigate the effect of herbicide Trifluralin and the role of magnetized water on enzymatic activities and content of proline and growth substances including gibberellin $\left(\mathrm{GA}_{3}\right)$ and cytokinin (6- benzyl amino purine), an experiment was conducted using squash (Cucurbita pepo L. var. Shiraz Hybrid F1) seedlings. Four levels of trifluralin $(0,5,15$ and $25 \mathrm{ppm})$ and irrigation by distilled and magnetized water were applied in a completely randomized design in 3 replicates at Urmia University in 2016. Different levels of trifluralin were added to pots 2 days after planting. Seedlings were treated by modified Hoagland solution with diurnal temperature $30: 18{ }^{\circ} \mathrm{C}$, relative humidity of 70-80 percent and light period of 16:8 hr, during a 5-week growing period in growth chamber. The effect of magnetized water and trifluralin on ornithine amino-transferase (OAT), proline dehydrogenase (PDH) and content of proline in both shoots and roots as well as $\mathrm{GA}_{3}$ and cytokinin was significant ( $\mathrm{p}>0.01$ ) according to ANOVA. The content of proline and OAT in roots and shoots as well as $\mathrm{GA}_{3}$ and cytokinin increased significantly, although the PDH of roots and shoots decreased under the influence of magnetized water. The content of proline and OAT increased and $\mathrm{GA}_{3}$, cytokinin and the activity of PDH declined by the increase of the levels of trifluralin. Overall, it can be concluded that the growth and biochemical indices of squash plants were improved by magnetized water under toxicity of herbicide trifluralin.
\end{abstract}

Keywords. cytokinin, gibberellin, ornithine aminotransferase, proline, proline dehydrogenase 
(Iqbal et al., 2012)، جذب عناصر غذايى، آسيميلاسيون و تحرى عناصر غذايى (Maheshwari \& Grewal, 2009)

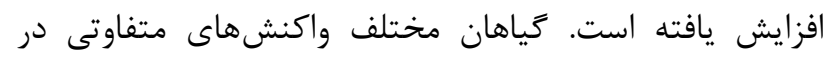
قبال آب مغناطيسى خواهند داشت ( Hozayn \& Abdul

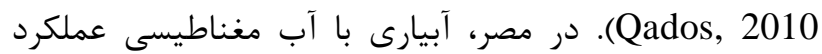

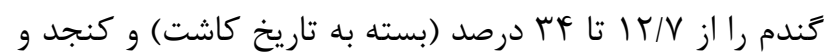

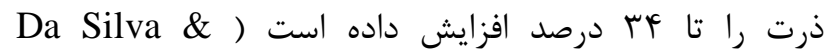
Dobranszki, 2014; Deshpande, 2014 با تأثير بر افزايش توليد فيتوهورمونهاى اسيد جيبرليك (GA3) كياه مىشود ) Basant \& Grewal, 2009; Turker et al., 2007). آب مغناطيسى به طور قابل ملاحظه فعاليت آنزيمهاى (

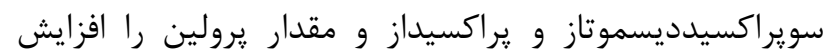

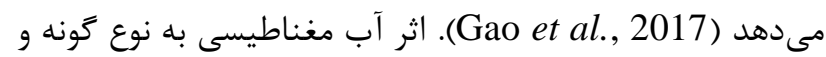

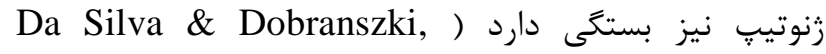
2014). آبيارى كياه لوبيا با آب مغناطيسى صفات رشدى، ردئ محتواى يتاسيم، جيبرليك اسيد، كينتين، اسيدهاى نوكلئيك، رنحَدانهاى فتوسنتزى، فعاليت فتوسنتزى و بازده انتقال مواد

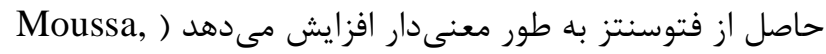

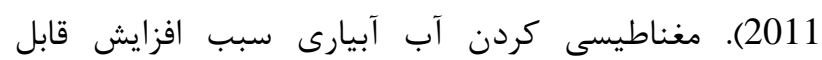
ملاحظه نفوذيذيرى آب مىشود ( .(al., 2011 با توجه به اين كه علفكش تريفلورالين مىتواند اثرات

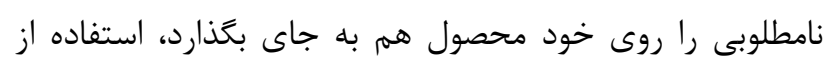
تركيبات و موجودات همزيست و برقرارى شرايطى كه به نحوى نداد ميزان سميت علفكشها را در جهت رسيدن به محصول بهينه،

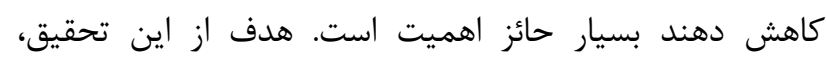

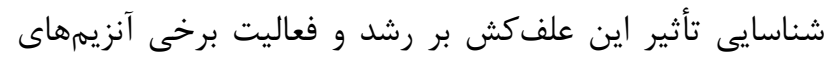
مسير يرولين و فيتوهورمونها در كياه كدو خورشتى تلقيح شده

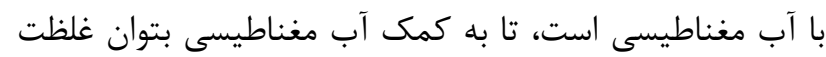
مؤثرى از علفكش را يافت كه علىرغم كنترل مناسب علفهاى

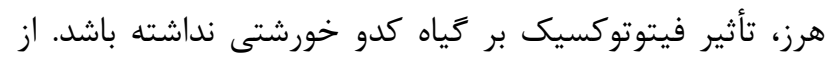

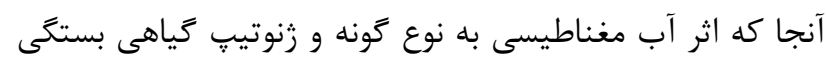

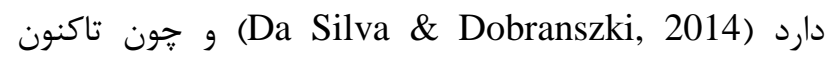
مطالعهاى جامع ريرامون اثرات حفاظتى آب مغناطيسى روى خصوصيات مورفولوزيكى، فيزيولوزيكى و بيوشيميايى كياه كدو

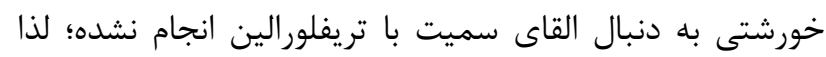

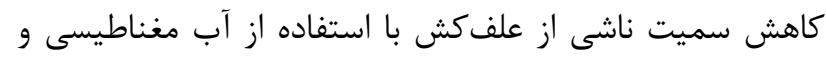

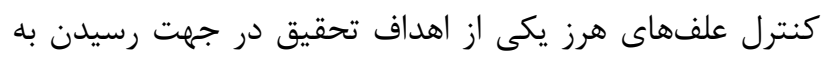
رشد بهتر كياه است.
مقامه

كنترل شيميايى علفهاى هرز در كشاورزى مدرن مرسوم

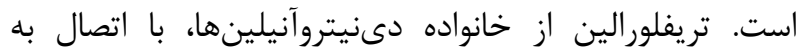
يروتئين توبولين ميكروتوبولها، باعث توقف تشكيل ديواره

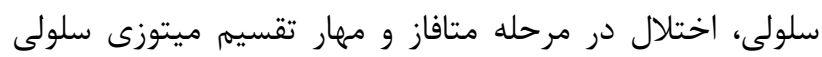

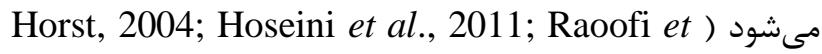
al., 2016 (al.). استفاده از علفكش تريفلورالين اثرات سوئى نيز بر روى كياه زراعى دارد (Moradbeigi \& Khara, 2011). آنتىاكسيدانهاى غيرآنزيمى مانند برولين و آسكوربيك اسيد، سلول را در مقابل تنش اكسيداتيو حفظ مي كنند ) (

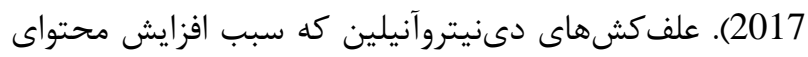
هيدركسى يرولين در ديواره سلولى و برخى اسيدهاى آمينه ازئين

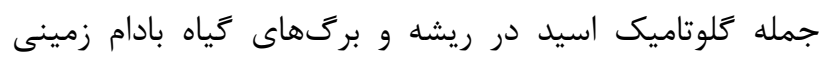

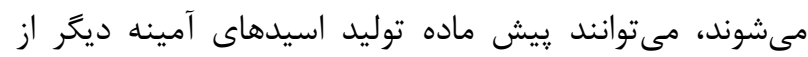

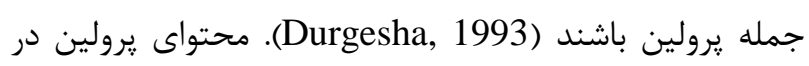

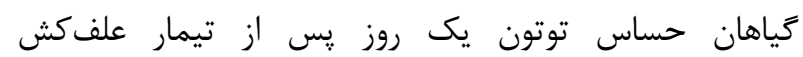

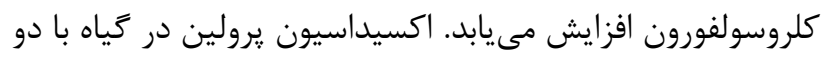

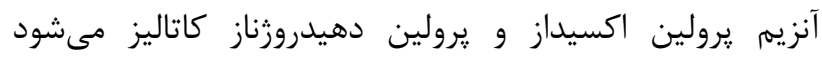
.(Toteva et al., 2004) ميدان مغناطيسى زمين در سيستمهاى زنده، بسيارى از

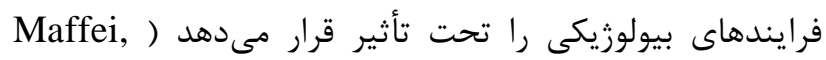

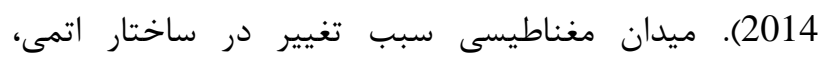
مولكولى و الكترونى آب و در نتيجه تغيير خصوصيات فيزيكى سئى آن مىشود (Da Silva \& Dobranszki, 2014). خوشههاى ״يوسته آب در اثر ميدان مغناطيسى به ذرات كوجكتر تبديل

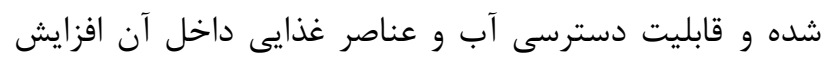

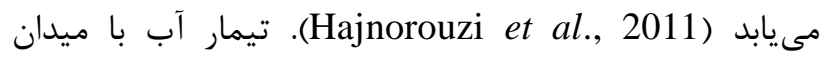
مغناطيسى سبب تأثير بر رشد كياه در سطح سلولى مىشود

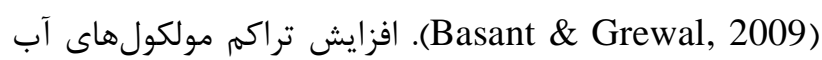

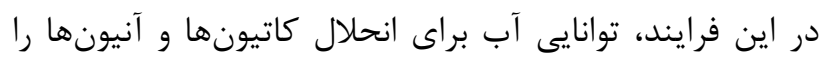

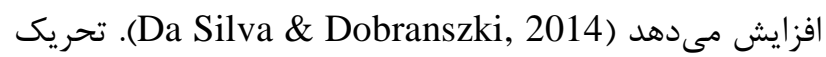

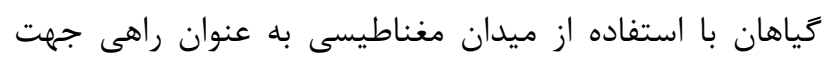

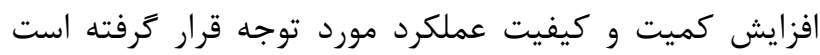

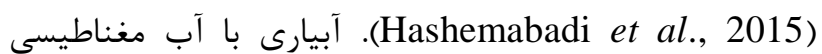
قادر به بهبود رشد كياه (Sadeghipour \& Aghaei, 2013) و جذب عناصر غذايى ( El Sayed \& El Sayed, 2014; Gao (et al., 2017 است. با استفاده از آب مغناطيسى، عملكرد دانه

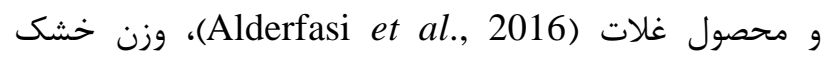

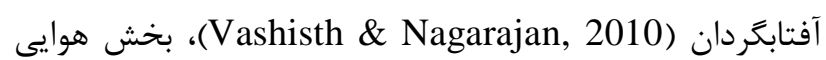
ذرت (Anand et al., 2012)، وزن دانه سنبله و عملكرد كَندم 
روش Sanchez و همكاران (Sanchez et al., 2001) با اندكى فئ آنير

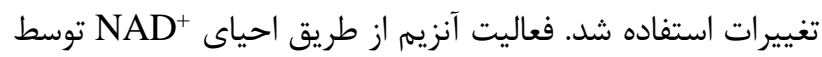

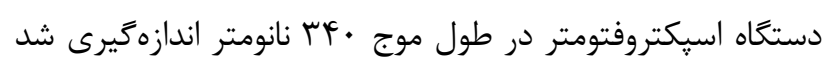

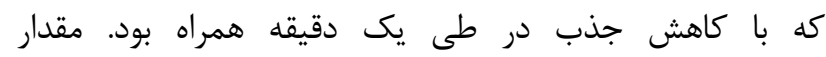
فيتوهورمونها با روش Bhalla

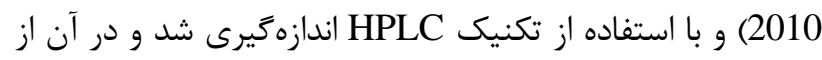
ستون C18 استفاده شد.

\section{نتابج و بحث}

آنزيم اورنيتين آمينوترانسفراز (OAT)

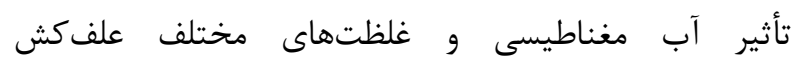

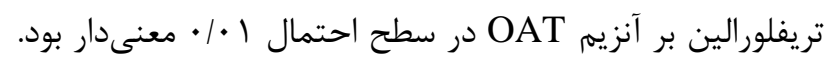

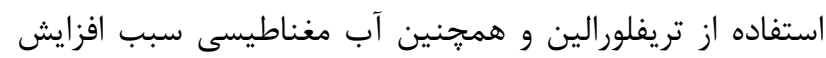

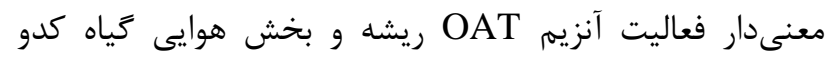

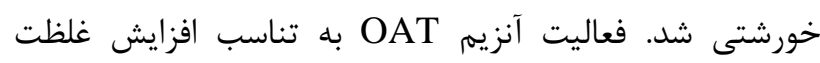

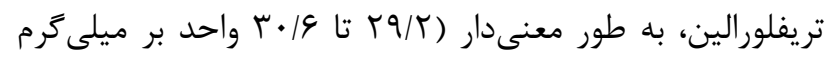

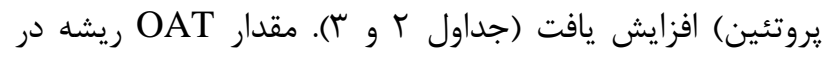

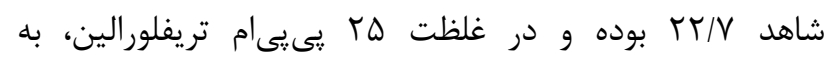

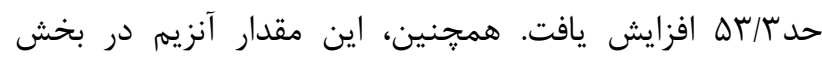

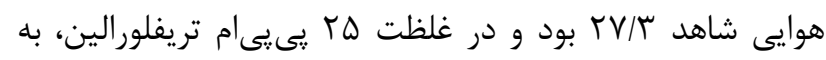

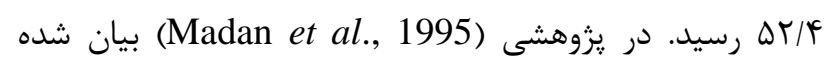
است كه تنش سبب افزايش فعاليت آنزيمهاى دركير در سنتز

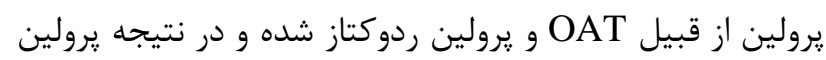

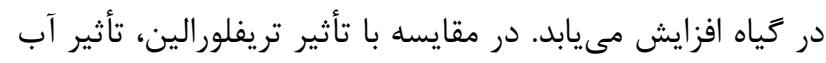

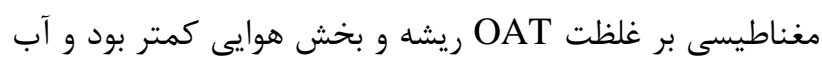

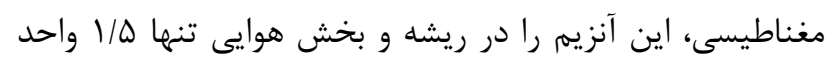
بر ميلى گرم يروتئين افزايش داد. آنزيم يروليندهيدروزناز (PDH)

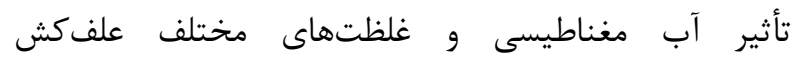

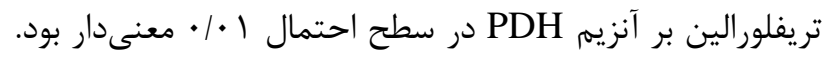

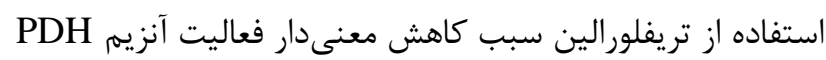

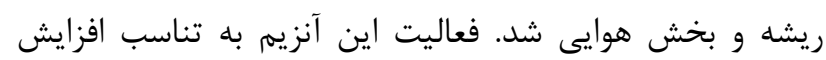

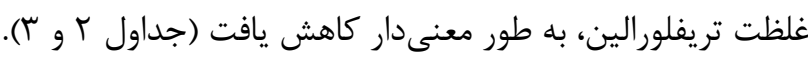
فعاليت PDH ريشه در شاهد

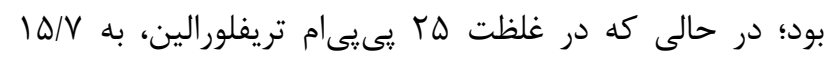

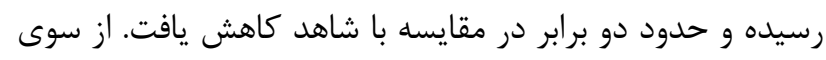
ديكر، فعاليت آن در بخش هوايى شاهد

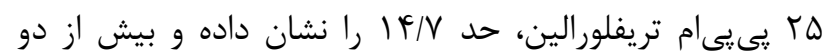

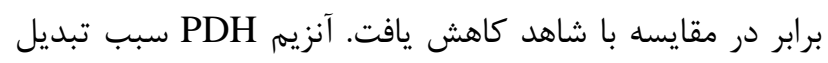

مواد و روش ها

اين آزمايش به صورت فاكتوريل در قالب طرح كرتهاى كاملاً

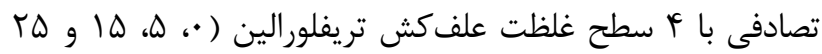

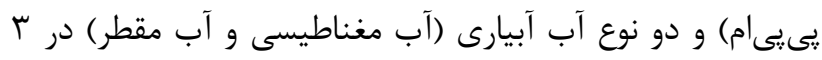

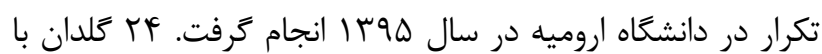
قطر r ا سانتىمتر و ارتفاع •ا سانتىمتر با محلول تجارى

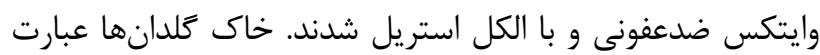

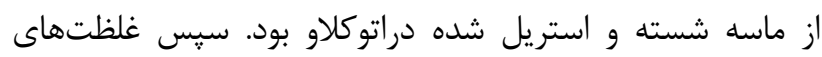
مختلف تريفلورالين دو روز قبل از كاشت به كلدانها اضافه شد. بذرهاى كدو خورشتى (Cucurbita pepo) واريته شيراز هيبريد

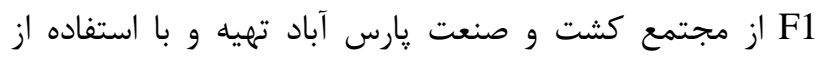
محلول هييوكلريت سديم •ا درصد بلمدت لها دقيقه ضدعفونى إنى سطحى شد. بذرهاى كدو داخل يك يار جه تميز و به مدت سه إد روز

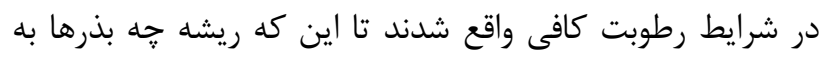

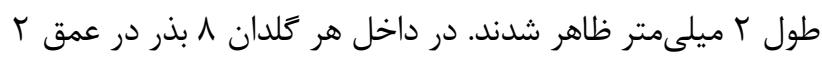
سانتىمترى سطح خاك كشت شد كه بعدا به تعداد ه بذر تنك

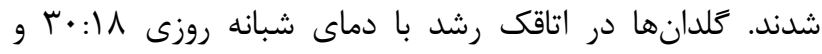

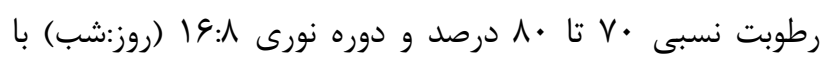

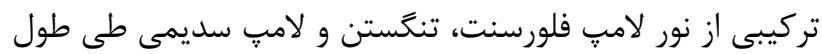

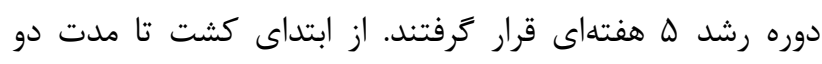

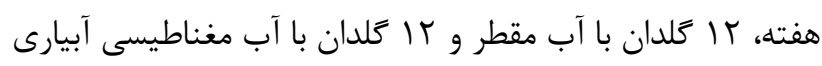

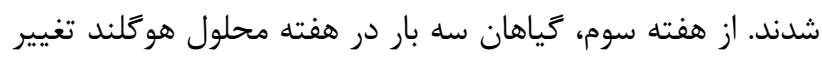

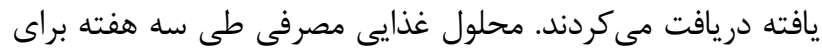

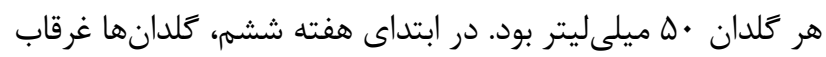

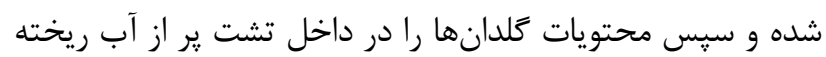
و ريشهها به آرامى شستشو داده شدند. براى آزمايشهايى كه نياز

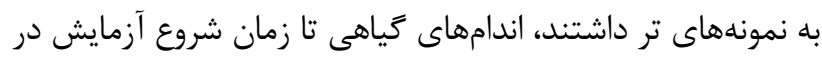

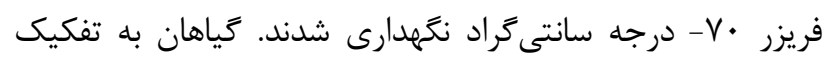
اندام هوايى و ريشه براى تحليلهاى رشدى و بيوشيميايى آماده

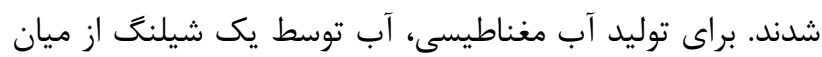

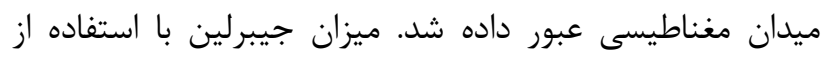

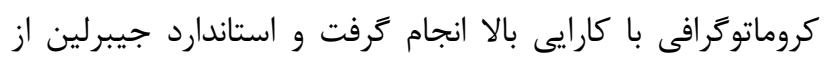

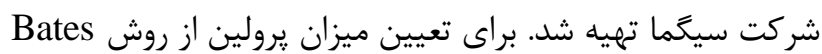

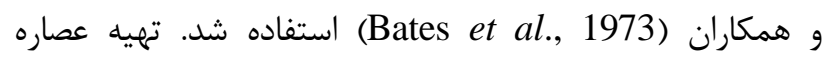

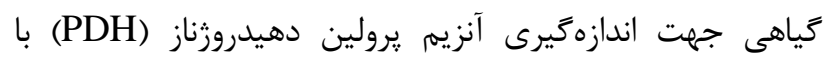

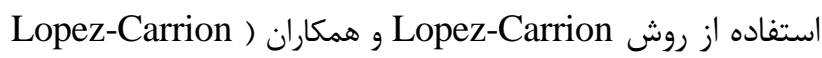
(et al., 2008

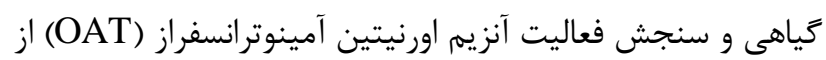


جدول ا- تجزيه واريانس صفات شيميايى در تيمارهاى مختلف آزمايشى.

Table 1. Analysis of variances of chemical traits at different treatments.

\begin{tabular}{|c|c|c|c|c|c|c|c|c|c|}
\hline \multicolumn{8}{|c|}{ ميانكين مربعات } & \multirow[t]{3}{*}{ df } & \multirow[t]{3}{*}{ منبع تغييرات } \\
\hline \multirow[t]{2}{*}{ جيبرليكاسيد } & \multirow[t]{2}{*}{ سيتوكينين } & \multicolumn{2}{|c|}{ برولين } & \multicolumn{2}{|c|}{ يروليندهيدروزناز } & \multicolumn{2}{|c|}{ اورنيتين آمينوترانسفراز } & & \\
\hline & & برى & ريشه & برى & ريشه & برك & ريشه & & \\
\hline$G / F \Delta r^{* * a}$ & $r \cdot / \Lambda f \cdot \cdots$ & $\cdot / r T \Delta^{\text {sta }}$ & $\cdot 1 \cdot r \varphi^{* t h}$ & $F \mid A / I V \varphi^{* *}$ & TGT/VD": & $\Lambda T \Delta / q 1 r^{* \#}$ & $\mid T \Delta F / F q=$ & $r$ & علفكش \\
\hline$V \cdot \mid q Y Y=\Rightarrow$ & $\Delta \cdot V / 199^{* *}$ & 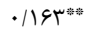 & $.1 .90^{* *}$ & 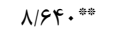 & $9 / 9 \uparrow \varphi^{*=4}$ & $\mid F / \cdot V \varphi^{=0.6}$ & $11 / \Delta V q^{* * *}$ & 1 & آبمغناطيسى \\
\hline$r / l \cdot \gamma^{* *}$ & 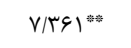 & $\cdot / \cdot 11^{* a}$ & $\cdot / \cdot r^{* * *}$ & $\cdot / \cdot 1 \cdot{ }^{\mathrm{ns}}$ & $\cdot / \cdot v \cdot{ }^{\mathrm{ns}}$ & $\cdot / \Gamma \Delta r^{\mathrm{ns}}$ & $\cdot / \cdot r q^{\mathrm{ns}}$ & r & اثرات متقابل \\
\hline.$/ \cdot \Delta r$ & $\cdot 1 \cdot \mathrm{v1}$ & $.1 . .1$ & $\cdot|\cdots \cdot|$ & $\cdot 11$. & . 499 & - /VTV & 1/FTa & 19 & خ خ خ \\
\hline
\end{tabular}

ns: non-significant; * and **: significant at 0.05 and 0.01 level, respectively

جدول r- فعاليتهاى آنزيمى اورنيتين آمينوترانسفراز و يرولين دهيدروزناز تحت تيمار آب مغناطيسى.

Table 2. OAT and PDH activity under magnetic water treatment.

\begin{tabular}{|c|c|c|c|c|}
\hline \multicolumn{2}{|c|}{ آنزيم يروليندهيدروزناز (U/mg protein) } & \multicolumn{2}{|c|}{ آنزيم اورنيتين آمينوترانسفراز (U/mg protein) } & \multirow{2}{*}{ آب مغناطيسى } \\
\hline بخشهوايى & ريشه & بخشهوايى & ل ريشه & \\
\hline$r / / 4 \cdot \pm V / \Delta \theta^{a}$ & $r r / / 9 \pm V / / r q^{a}$ & $k r / q f \pm 1 \cdot / \lambda r^{b}$ & $F r / \Delta q \pm / r / l V \cdot b$ & 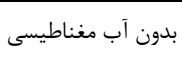 \\
\hline$r \cdot / r \cdot \pm V / \Delta g r^{b}$ & $r \cdot / \Lambda \Lambda \pm 9 / 9 \Delta \Delta^{b}$ & $f \Delta / A V \pm 1 \cdot / 4 r r^{a}$ & $\varphi q / 9 \Lambda \pm 1 \% / . q V^{a}$ & با آب مغناطيسى \\
\hline
\end{tabular}

ميانكينهاى داراى حروف مشترك در يك ستون از لحاظ آمارى يكسان هستند.

The means with common alphabets are statistically the same.

جدول س- فعاليتهاى آنزيمى اورنيتين آمينوترانسفراز و يرولين دهيدروزناز در سطوح مختلف غلظت تريفلورالين.

Table 3. OAT and PDH activity under different concentrations of trifluralin.

\begin{tabular}{|c|c|c|c|c|}
\hline \multicolumn{2}{|c|}{ آنزيم يروليندهيدروزناز (U/mg protein) } & \multicolumn{2}{|c|}{ آنزيم اورنيتينآمينوترانسفراز (U/mg protein) } & \multirow{2}{*}{ غلظت علف كش } \\
\hline بخش هوايى & 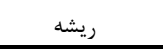 & بخش هوايى & 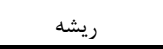 & \\
\hline$r T / q r \pm \cdot / V \cdots a$ & $r T / 9 T \pm \cdot / 9 r r a$ & $r V / r \wedge \pm 1 / V q \varphi^{d}$ & $r r / V \cdot \pm r / \cdot 19^{c}$ & . \\
\hline $19 / 9 r \pm \cdot / 1 \ldots b$ & $19 / V r \pm \cdot / \Lambda r \Lambda^{b}$ & $|F N / F| \pm \cdot / 9 \Lambda \cdot{ }^{c}$ & $4 q / q \cdot \pm \cdot / V \vee I^{b}$ & $\Delta$ \\
\hline $10 / 9 V \pm \cdot / V 19^{c}$ & $I V / V \Delta \pm \cdot / 9 \Delta q^{c}$ & $\Delta \cdot 199 \pm \cdot / V 9 V^{b}$ & $\Delta / / \backslash V \pm \| / \cdot \Delta r^{\mathrm{a}}$ & 10 \\
\hline$|f / V \cdot \pm \cdot| q \mu q^{d}$ & $|Q / 9 \Lambda \pm \cdot| q \mu \cdot{ }^{\mathrm{d}}$ & $\Delta r / F \Psi \pm \cdot / V \Delta V^{\mathrm{a}}$ & $\Delta r / r q \pm \cdot / \Lambda V q^{a}$ & ra \\
\hline
\end{tabular}

ميانكَينهاى داراى حروف مشتر ك در يك ستون از لحاظ آمارى يكسان هستند.

The means with common alphabets are statistically the same.

تأثير آب مغناطيسى و علفكش تريفلورالين بر پرولين ريشه و

بخش هوايى و اثرات متقابل بين دو عامل در سطح احتمال I ا • |

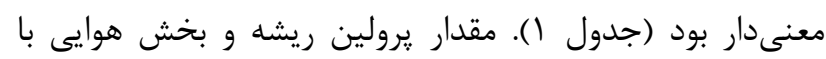
استفاده از آب مغناطيسى افزايش يافت كدود اين نتايج با يافتهها

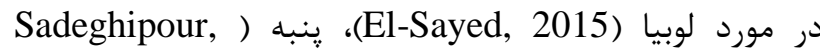
(2015; Gao et al., 2017 يرولين همراه با افزايش يروتئين در اثر آب مغناطيسى ممكن است سبب افزايش عملكرد گياه شود (El-Sayed, 2015). يرولين در شرايط تنش در بافت گياه انباشته شده و پس از رفع تنش، نقش مهمى در بهبود كياه دارد (Singh et al., 2000). آب مغناطيسى با افزايش يرولين و فعاليت آنزيمهاى آنتى Sadeghipour, ) اكسيدانت نقش مهمى در تعديل تنش دارد

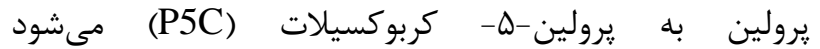

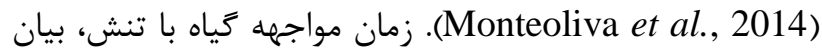
زن كدكننده آنزيم يرولين-ها - كربوكسيلات سنتتاز افزايش يافته و مانع بيان زن PDH و كاهش آن در بافت زياه مىشود

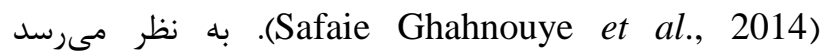
تريفلورالين مانند تنش براى گياه عمل كرده، در نتيجه فعاليت يرولين دهيدروزناز كاهش يافته و در اين شرايط گيرولين در زياه

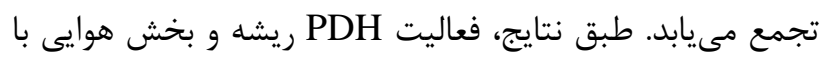
استفاده از آب مغناطيسى بهطور معنى يابدار در مقايسه با شاهد

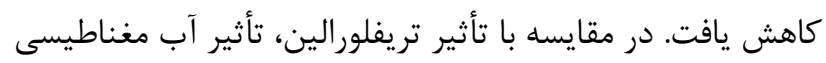
بر غلظت اين آنزيم كمتر بود و آب مغناطيسى سبب كاهش تنها ا 1/ واحد بر ميلى كرم بروتئين شد. 


\section{همبستكى فعاليت آنزيمهاى PDH و OAT با برولين ريشه و}

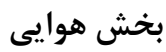

همبستخى بين فعاليت OAT بخش هوايى هوايى و ريشه گياه با

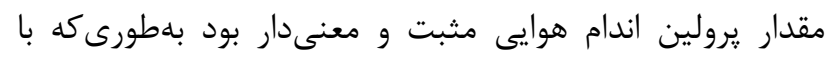

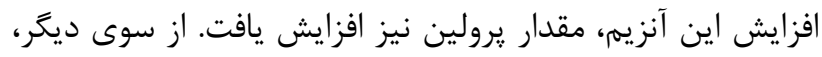

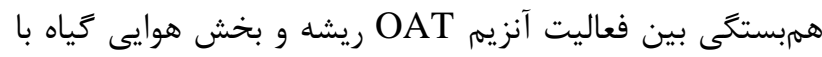

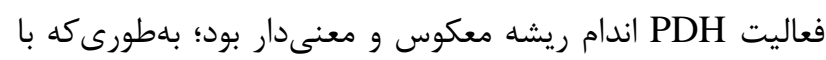
افزايش OAT، فعاليت PDH كاسته شد.

\section{سيتوكينين و جيبرلين}

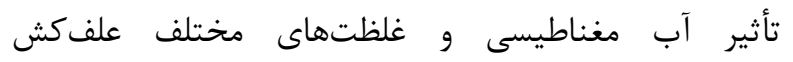

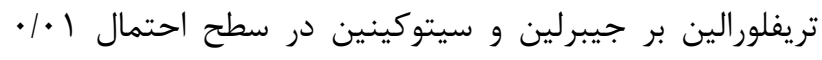

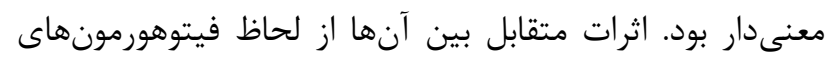

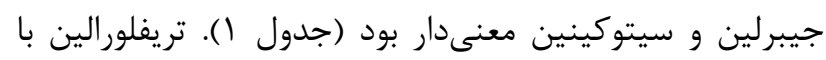
ايجاد تنش در كياه سبب كاهش معنى دار مقدار سيتوكينين و و جيبرليك اسيد شد. كاهش مقدار سيتوكينين درونزاد در Shashidhar et al., ) واكنش به تنشها مشاهده شده است

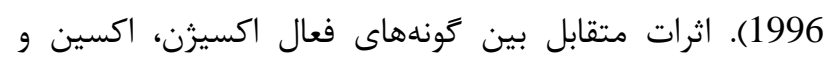

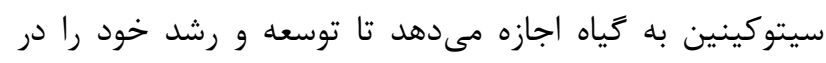
شرايط غيرمساعد بيرونى تعديل كند (Bielach et al., 2017).

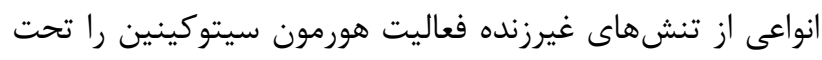

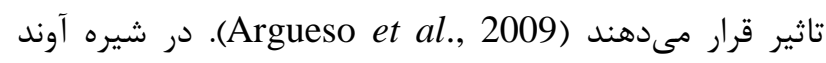

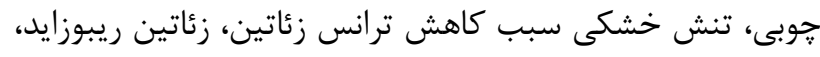

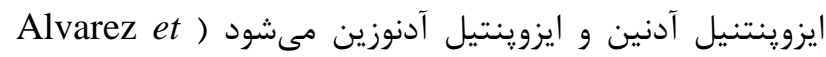

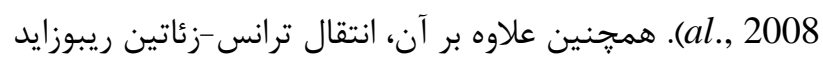

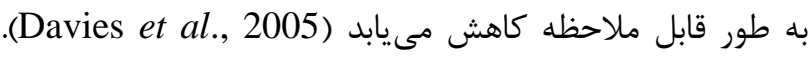

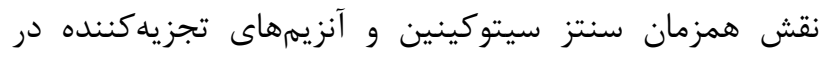
ياسخ به تنش، احتمالا به الكوهاى بيان فضايى و موقتى آنسين آنها

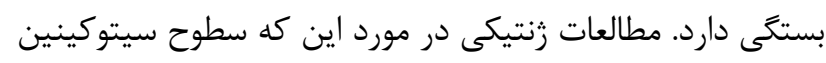

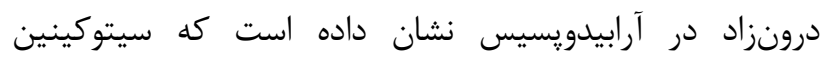

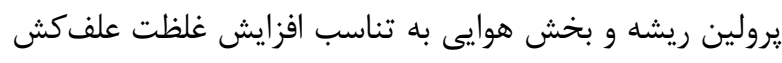

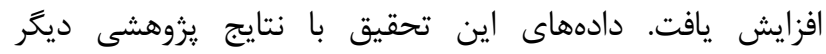

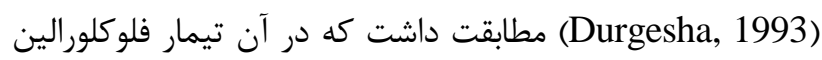

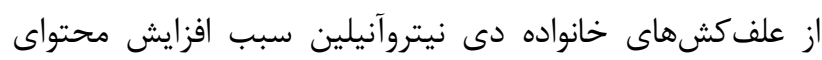

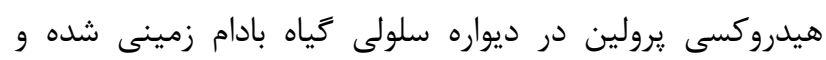

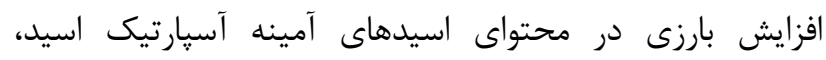

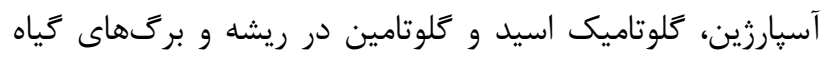

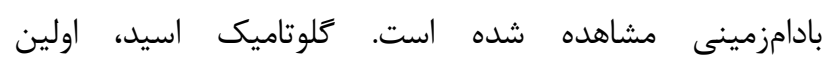

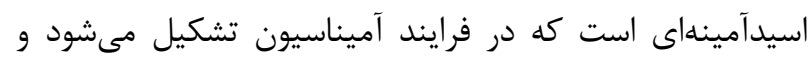

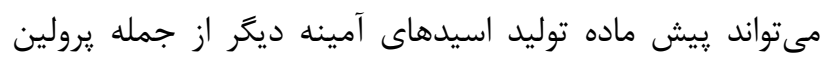

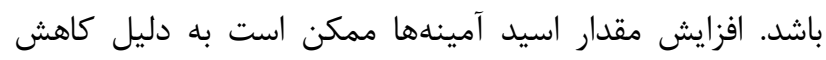

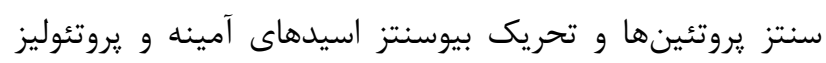

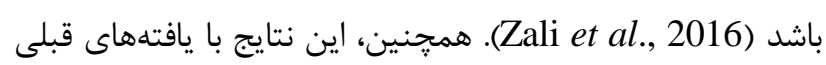
(Moradbeigi \& Khara, 2011) افزايش غلظت علفكش تريفلورالين، محتواى يرولين و اسيدهاى

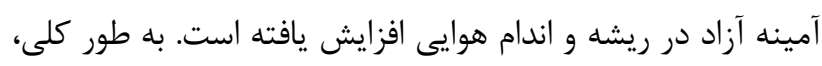

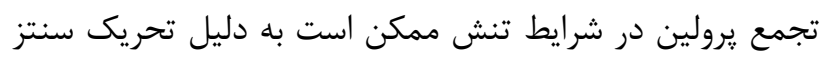

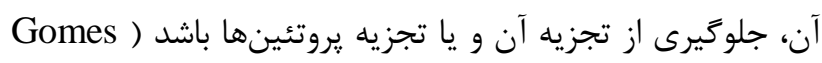

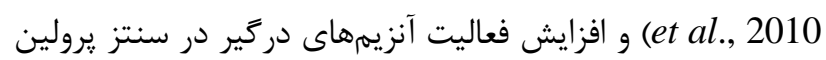

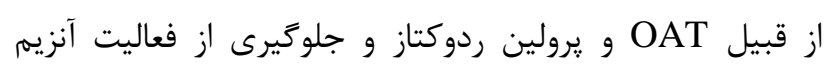

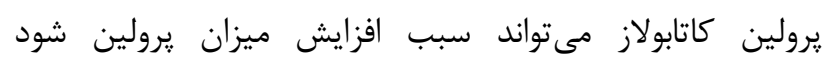

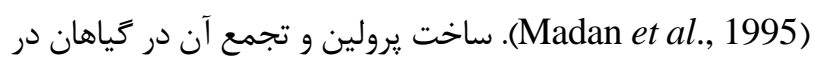
نتيجه تنشهاى محيطى ممكن است از طريق تحريك سنتز

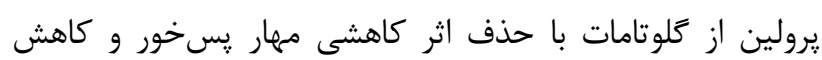

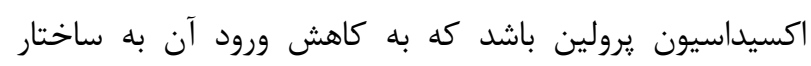

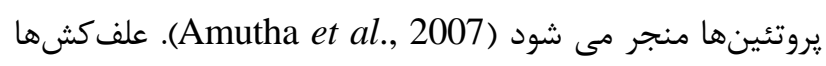

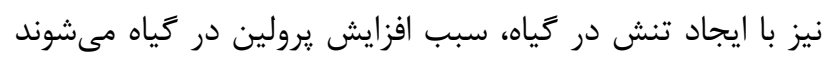

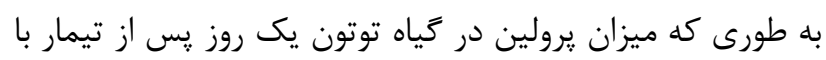
كلروسولفورون افزايش يافت (Toteva et al., 2004).
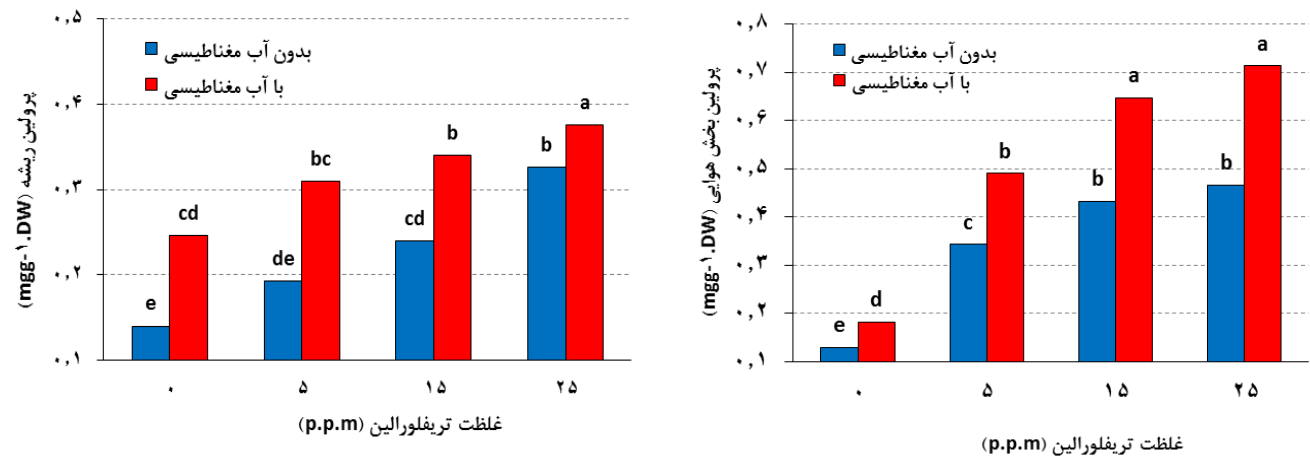

شكل ا- محتواى برولين ريشه و بخش هوايى تحت غلظتهاى مختلف تريفلورالين و تيمار آب مغناطيسى.

Fig. 1. Root and shoot proline content under different concentrations of trifluralin and magnetic water treatment. 

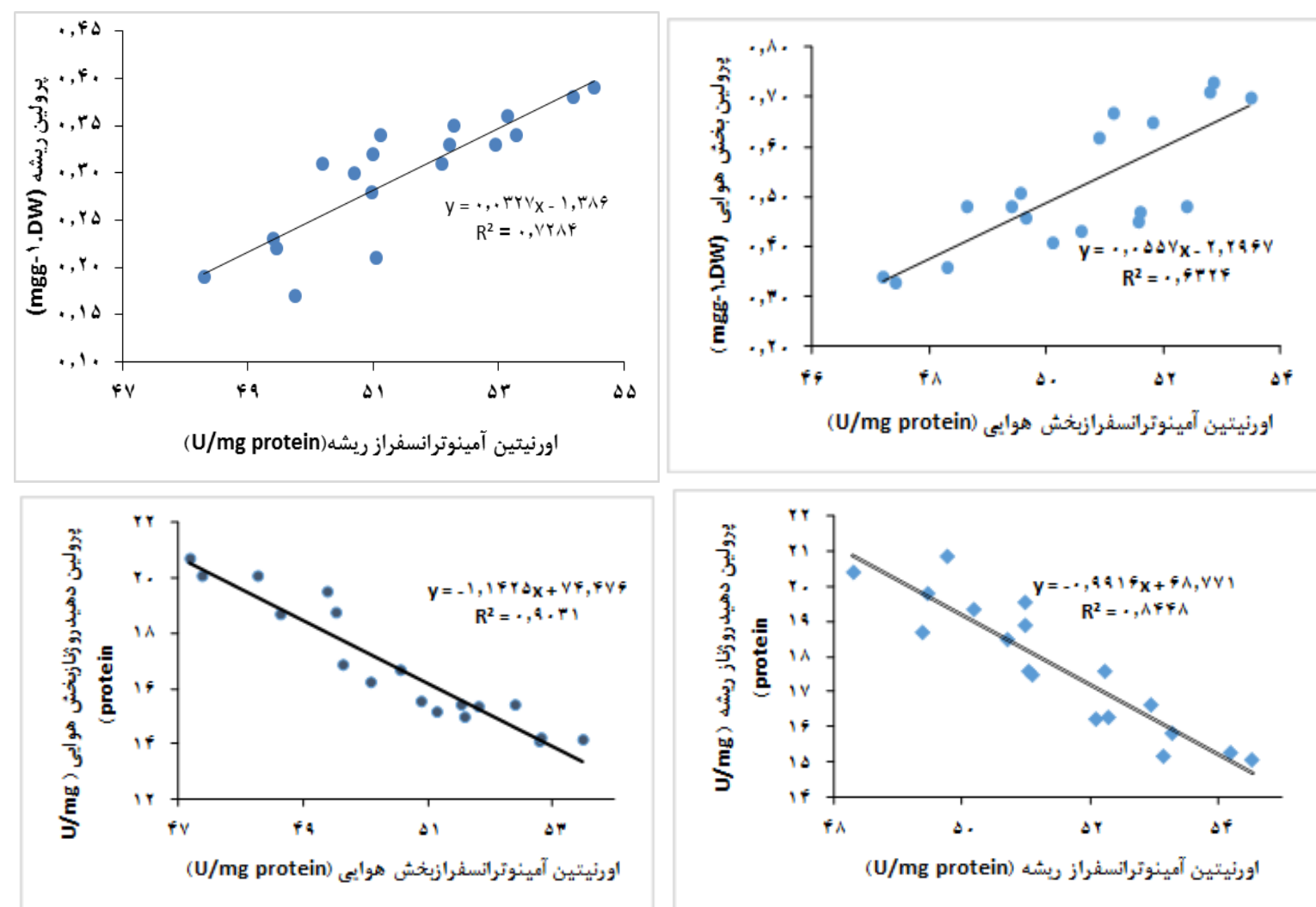

شكل r - همبستكى فعاليت اورنيتين آمينوترانسفراز با يرولين بخش هوايى و ريشه و فعاليت يرولين دهيدروزناز.

Fig. 2. Correlation of the activity of ornithine aminotransferase with root and shoot proline and the activity of proline dehydrogenase.

كلاس تاو در اثر فعاليت بالاى كلوتاتيون يراكسيداز، سبب تحمل

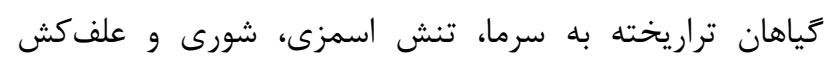

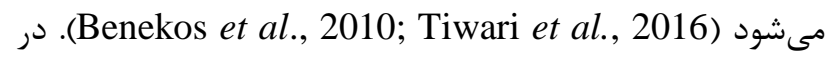
تمامى غلظتهاى تريفلورالين، مقدار سيتوكينين و جيبرليك اسيد با استفاده از آب مغناطيسى بلهطور معنىى ترار افزايش يافتئ. اين نتايج با يافتههاى Basant و بrewal آفتابگردان مطابقت داشت. همجنين افزايش غلظت كلروفيل و
نقش منفى در ياسخ به تنش بازى مى كند ( )

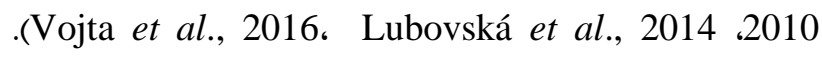
كاهش مقدار سيتوكينين منجر به بهبود تحمل تنش شورى و خشكى مىشود ( Wishiyama et al., 2011

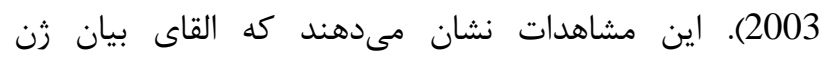
GSTU5

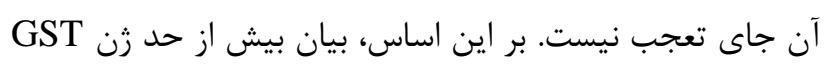
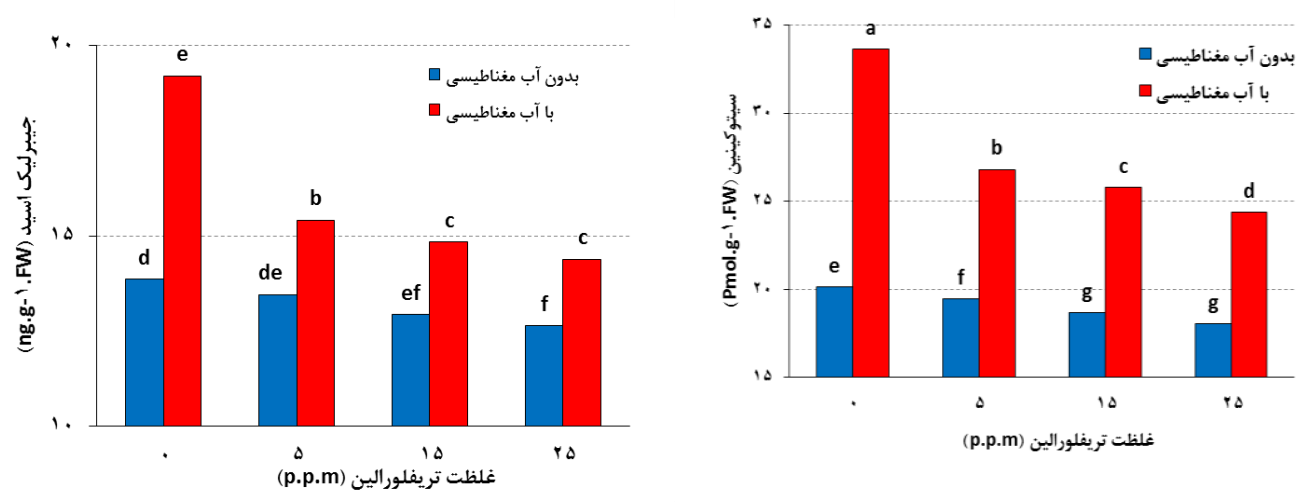

شكل س - محتواى فيتوهورمونهاى ريشه و ساقه در غلظتهاى مختلف تريفلورالين و تيمار آب مغناطيسى.

Fig. 3. Root and shoot phytohormones content at different concentrations of trifluralin and magnetic water treatment. 


\section{REFERENCES}

Alderfasi, A.A., Al-Suhaibani, N.A., Selim, M.M. and AlHammad, B.A.A. 2016. Using magnetic technologies in management of water irrigation programs under arid and semi-arid ecosystem. - Adv. Plant Agric. Res. 3: 109-116.

Alvarez, S., Marsh, E.L., Schroeder, S.G. and Schachtman, D.P. 2008. Metabolomic and proteomic changes in the xylem sap of maize under drought. Plant Cell Environ. 31: 325-340.

Amutha, R., Muthulaksmi, S., Baby Rani, W., Indira, K. and Mareeswari, P. 2007. Studies on biochemical basis of heat tolerance in sunflower (Helianthus annuus L.). - Res. J. Agric. Biol. Sci. 3: 234-238.

Anand, A., Nagarajan, S., Verma, A.P.S., Joshi, D.K., Pathak, P.C. and Bhardwaj, J. 2012. Pre- treatment of seeds with static magnetic field ameliorates soil water stress in seedling of maize (Zea mays L.). - Ind. J. Biochem. Biophys. 49: 63-70.

Argueso, C.T., Ferreira, F.J. and Kieber, J.J. 2009. Environmental perception avenues: The interaction of cytokinin and environmental response pathways. Plant Cell Environ. 32: 1147-1160.

Bhalla, K., Singh, S.B. and Agarwal, R. 2010. Quantitative determination of gibberellins by high performance liquid chromatography from various gibberellins producing Fusarium strains. - Environ. Monit. Assess. 167: 515- 520.

Basant, L.M. and Grewal, H.S. 2009. Magnetic treatment of irrigation water: Its effects on vegetable crop yield and water productivity. - Agric. Water Manage. 96: 1229-1236.

Bates, L.S., Waldren, R.P. and Teare, I.D. 1973. Rapid determination of free proline for water-stress studies. - Plant Soil. 39: 205-207.

Benekos, K., Kissoudis, C., Nianiou-Obeidat, I., Labrou, N., Madesis, P., Kalamaki, M., Makris, A. and Tsaftaris, A. 2010. Overexpression of a specific soybean GmGSTU4 isoenzyme improves diphenyl ether and chloroacetanilide herbicide tolerance of transgenic tobacco plants. - J. Biotech. 150: 195-201.

Bielach, A., Hrtyan, M. and Tognetti, V.B. 2017. Plants under stress: Involvement of auxin and cytokinin, Review. - Int. J. Mol. Sci. 18: E1427. doi: 10.3390/ijms18071427.

Da Silva, J.A.T. and Dobranszki, J. 2014. Impact of magnetic water on plant growth. - Environ. Exp. Biol. 12: $137-142$.

Davies, W.J., Kudoyarova, G. and Hartung, W. 2005. Long-distance ABA signaling and its relation to other signaling pathways in the detection of soil drying and the mediation of the Plant's response to drought. - J. Plant Growth Regul. 24: 285-295.

Deshpande, M. 2014. Effect of magnetic water on growth of legumes. - Euro. J. App. Eng. Sci. Res. 3: 9-12.

Durgesha, M. 1993. Effect of fluchloralin on protein synthesis, free amino acids and hydroxyproline content in groundnut (Arachis hypogaea L.). - Ann. App. Biol. 123: 703-708.

El Sayed, H. and El Sayed, A. 2014. Impact of magnetic water irrigation for improve the growth, chemical composition and yield production of broad bean (Vicia faba L.) plant. - Am. J. Exp. Agric. 4: 476-496.
جيبرليك اسيد در آفتابگردان (Turker et al., 2007) و جيبرليك اسيد در لوبيا (El-Sayed, 2015) و و افزايش سيتوكينين در حندم (Hozayn \& Abdul Qados, 2010) با نتايج تحقيق حاضر مطابقت داشت. افزايش سيتوكينين ممكن است از تأثير ميدان مغناطيسى بر تغيير كليدى فرايندهاى مابنى سلولى ازجمله رونويسى زن باشد كه نقش مهمى را در تغيير فرايندهاى سلولى دارد ( El-Sayed, 2015). در صورت كاهش رن ميزان سيتوكينين و جيبرليك اسيد در اثر تنش ناشى از علف كش تريفلوالين، استفاده از آب مغناطيسى جهيت آنهين بهبود ميزان هورمونهاى گياهى مذكور راهكار نويدبخشى است.

$$
\text { نتيجه تيرى }
$$

در اين تحقيق بازدارندگى فعاليت آنزيم PDH ضمن افزايش

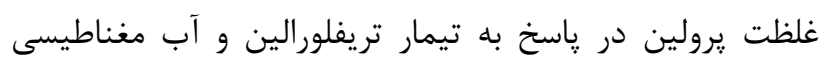

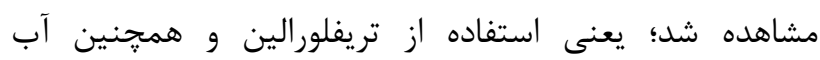

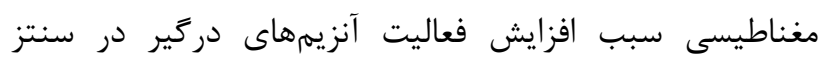
يرولين از قبيل OAT و كاهش آنزيمهاى تجزيه كننده يرولين از ئن جمله PDH و درنتيجه افزايش معنىدار پرولين ريشه و بخش هوايى گياه كدو خورشتى شد. در زمان مواجهه زياه با تنش (مثلا تريفلورالين) و در تيمار آب مغناطيسى، بيان زن كدكنئن

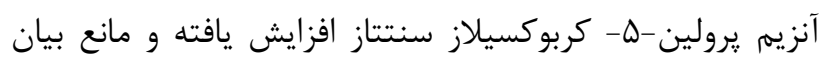
زن PDH و كاهش آن در بافت زياه مىشود. تريفلورالين سبب

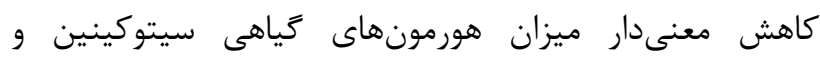

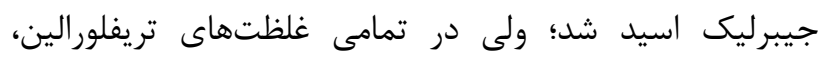

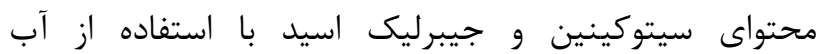
مغناطيسى به طور معنى دار در مقايسه با شاهد افزايش يافت. آب مغناطيسى با تأثير بر توليد فيتوهورمونها سبب بهني بهبود فعاليت

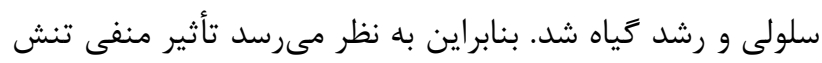
علف كش بر هورمون هاى گياهى سيتوكينين و جيبرليك اسيد رانئ

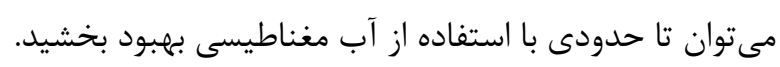

$$
\text { سياسگزارى }
$$

بدينوسيله از دانشعاه اروميه به سبب تأمين مالى اين مطالعه

$$
\text { قدردانى مىشود. }
$$


El-Sayed, H.E.S.A. 2015. Impact of magnetic water irrigation to improve the growth, chemical composition and yield production of broad bean (Vicia faba L.) plant. - Nat. Sci. 13: 107-119.

Gao, Y., Sun, Y., Zhang, R. and Chu, G. 2017. Effects of magnetic water irrigation on the growth, $\mathrm{N}$ uptake and antioxidant enzyme activities of cotton seedlings. $-\mathbf{J}$. Agric. Sci. Technol. 7: 25-33.

Gomes, F.P., Oliva, M.A., Mielke, M.S., Almeida, A.A.F. and Aquino, L.A. 2010. Osmotic adjustment, proline accumulation and membrane stability in leaves of Cocos nuciera submitted to drought stress. - Sci. Horti. 126: 379-384.

Hajnorouzi, A., Vaezzadeh, M., Ghanati, F., Jamnezhad, H. and Nahidian, B. 2011. Growth promotion and a decrease of oxidative stress in maize seedlings by a combination of geomagnetic and weak electromagnetic fields. - J. Plant Physiol. 168: 1123-1128.

Hashemabadi, D., Zaredost, F. and Jadid Solimandarabi, M. 2015. The effect of magnetic water and irrigation intervals on the amount of the nutrient elements in soil and aerial parts of periwinkle (Catharanthus roseus L.). - J. Ornament. Plant. 5: 139-149.

Horst, V. 2004. Further root colonization by arbuscular mycorrhizal fungi in already mycorrhizal plants in suppressed after a critical level of root colonization. Plant Physiol. 161: 339-341.

Hoseini, M., Ghorbani, R. and Bagheri, A. 2011. Evaluate the performance of different herbicides to control weeds in garlic. - Iran Agric. Res. 9: 463-473.

Hozayn, M. and Abdul Qados, A.M.S.A. 2010. Magnetic water application for improving wheat (Triticum aestivum L.) crop production. - Agric. Biol. J. North Am. 1: 677-682.

Iqbal, M., Haq, Z.U., Jamil, Y. and Ahmad, M.R. 2012. Effect of presowing magnetic treatment on properties of pea. - Int. Agrophys. 26: 25-31.

Lopez-Carrion, A.I., Castellano, R., Rosales, M.A., Ruiz, J.M. and Romero, L. 2008. Role of nitric oxide under saline stress: implications on proline metabolism. Biol. Plant. 52: 587-591.

Lubovská, Z., Dobrá, J., Štorchová, H., Wilhelmová, N. and Vanková, R. 2014. Cytokinin oxidase/dehydrogenase overexpression modifies antioxidant defense against heat, drought and their combination in Nicotiana tabacum plants. - J. Plant Physiol. 171: 1625-1633.

Madan, S., Nainawatee, H.S., Jain, R.K. and Chowdhury, J.B. 1995. Proline and proline metabolising enzymes in in-vitro selected $\mathrm{NaCl}$ tolerant Brassica juncea L. under salt stress. - Ann. Bot. 76: 51-57.

Maffei, E.M. 2014. Magnetic field effects on plant growth, development, and evolution. - Front. Plant Sci. 5: 1-15.

Maheshwari, B.L. and Grewal, H.S. 2009. Magnetic treatment of irrigation water: its effects on vegetable crop yield and water productivity. - Agric. Water Manage. 96: 1229-1236.

Monteoliva, M.I., Rizzi, Y.S., Cecchini, N.M., Hajirezaei, M.R. and Alvarez, M.E. 2014. Context of action of proline dehydrogenase (ProDH) in the hypersensitive response of Arabidopsis. - BMC Plant Biol. 13: 14-21.

Moradbeigi, H. and Khara, J. 2011. An evaluation of some physiological and biochemical parameters resulting from interaction of herbicide trifluralin and mychorrizal colonization by Glomus versiforme in sunflower plants (cv. Lakomka). - J. Plant Biol. 3: 5970.

Mostafazadeh-Fard, B., Khoshravesh, M., Mousavi, S.F. and Kiani, A.R. 2011. Effects of magnetized water and irrigation water salinity on soil moisture distribution in trickle irrigation. - J. Irri. Drain. Eng. 137: 398-402.

Moussa, H.R. 2011. The impact of magnetic water application for improving common bean (Phaseolus vulgaris) production. - New York Sci. J. 4: 15-20.

Nishiyama, R., Watanabe, Y., Fujita, Y., Le, D.T., Kojima, M., Werner, T., Vankova, R., YamaguchiShinozaki, K., Shinozaki, K., Kakimoto, T., Sakakibara, H., Schmulling, T. and Tran, L.S. 2011. Analysis of cytokinin mutants and regulation of cytokinin metabolic genes reveals important regulatory roles of cytokinins in drought, salt and abscisic acid responses and abscisic acid biosynthesis. - Plant Cell. 23: 2169-2183.

Raoofi, M., Mahzari, S., Baghestani, M.A. and Giti, S. 2016. Effects of applying different herbicides dosages Oxyfluorfen and Trifluralin on morphological, economical and biological yield of garlic (Allium sativum L.). - Int. J. Adv. Biol. Biomed. Res. 4: 136142.

Sadeghipour, O. 2015. Magnetized water alleviates drought damages by reducing oxidative stress and proline accumulation in mung bean (Vigna radiata L. Wilczek). - Bull. Environ. Pharmacol. Life Sci. 4: 62-69.

Sadeghipour, O. and Aghaei, P. 2013. Improving the growth of cowpea (Vigna unguiculata L. Walp.) by magnetized water. - J. Bio. \& Env. Sci. 3: 37-43.

Safaie Ghahnouye, Z., Shahbazi, E., Salavati, A. and Shafeinia, A.R. 2014. An investigation on effect of salinity on expression of proline dehydrogenase gene in canola cv. 401 and double haploid line 3. $-1^{\text {st }}$ Conf. New Find. Environ. Agric. Ecosys. Tehran Univ.

Sanchez, E., Lopez-Lefebre, L.R., García, P.C., Rivero, R.M., Ruiz, J.M. and Romero, L. 2001. Proline metabolism in response to highest nitrogen dosages in green bean plants (Phaseolus vulgaris L. cv. Strike). J. Plant Physiol. 158, 593-598.

Shashidhar, V.R., Prasad, T.G. and Sudharshan, L. 1996. Hormone signals from roots to shoots of sunflower (Helianthus annuus L.) moderate soil drying increases delivery of abscisic acid and depresses delivery of cytokinins in xylem sap. - Ann. Bot. 78: 151-155.

Singh, D.K., Sale, P.W.G., Pallaghy, C.K. and Singh, V. 2000. Role of proline and leaf expansion rate in the recovery of stressed white clover leaves with increased phosphorus concentration. - New Phytol. 146: 261-269.

Tiwari, V., Patel, M.K., Chaturvedi, A.K., Mishra, A. and Jha, B. 2016. Functional characterization of the 
Tau class glutathione $\mathrm{S}$ transferases gene (SbGSTU) promoter of Salicornia brachiata under salinity and osmotic stress. - PLoS ONE. 11: e0148494.

Toteva, T., Slavov, V.S., Batchvarova, R., Batchvarova, A. and Stefanov, D. 2004. Stress markers in chlorsulphouron tolerant transgenic tobacco plants. Plant Physiol. 30: 103-111.

Turker, M., Temirci, C., Battal, P. and Erez, M.E. 2007. The effects of an artificial and static magnetic field on plant growth, chlorophyll and phytohormone levels in maize and sunflower plants. - Phyton 46: 271-284.

Vashisth, A. and Nagarajan, S. 2010. Effect on germination and early growth characteristics in sunflower (Helianthus annuus) seeds exposed to static magnetic field. - J. Plant Physiol. 167: 149-56.

Vojta, P., Kokáš, F., Husǐcková, A., Grúz, J., Bergougnoux, V., Marchetti, C.F., Jiskrová, E., Ježilová, E., Mik, V., Ikeda, Y. and Galuszka, P. 2016. Whole transcriptome analysis of transgenic barley with altered cytokinin homeostasis and increased tolerance to drought stress. - New Biotechnol. 33: 676-691.

Werner, T., Nehnevajova, E., Kollmer, I., Novak, O., Strnad, M., Kramer, U. and Schmulling, T. 2010. Root-specific reduction of cytokinin causes enhanced root growth, drought tolerance and leaf mineral enrichment in Arabidopsis and tobacco. - Plant Cell. 22: 3905-3920.

Werner, T., Motyka, V., Laucou, V., Smets, R., Van Onckelen, H. and Schmülling, T. 2003. Cytokinindeficient transgenic Arabidopsis plants show multiple developmental alterations indicating opposite functions of cytokinins in the regulation of shoot and root meristem activity. - Plant Cell. 15: 2532-2550.

Zali, H., Hassanlou, T., Sofalian, O., Asghari, A. and Zeinolabedini, M. 2016. Drought stress effect on physiological parameter and amino acids accumulations in canola. - J. Crop Breed. 8: 191-203.

How to cite this article:

Esmailnejad, N., Khara, J. and Akhgari, M. 2020. The effect of magnetized water on the growth and some biochemical parameters of squash (Cucurbita pepo) plants under toxicity of herbicide trifluralin. - Nova Biol. Reperta 6: 478-486. (In Persian)

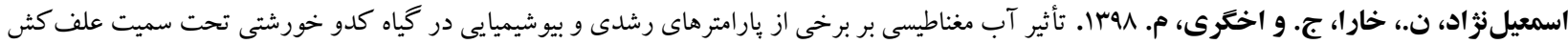

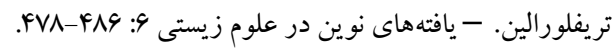

